\title{
Improved Chemical Control of Chagas Disease Vectors in the Dry Chaco Region
}

Author(s): María Carla Cecere, Gonzalo M. Vazquez-Prokopec , Leonardo A. Ceballos, Silvana Boragno, Joaquín E. Zárate, Uriel Kitron, and Ricardo E. Gürtler Source: Journal of Medical Entomology, 50(2):394-403. 2013.

Published By: Entomological Society of America

URL: http://www.bioone.org/doi/full/10.1603/ME12109

BioOne (www.bioone.org) is a nonprofit, online aggregation of core research in the biological, ecological, and environmental sciences. BioOne provides a sustainable online platform for over 170 journals and books published by nonprofit societies, associations, museums, institutions, and presses.

Your use of this PDF, the BioOne Web site, and all posted and associated content indicates your acceptance of BioOne's Terms of Use, available at www.bioone.org/page/terms_of_use.

Usage of BioOne content is strictly limited to personal, educational, and non-commercial use. Commercial inquiries or rights and permissions requests should be directed to the individual publisher as copyright holder. 


\title{
Improved Chemical Control of Chagas Disease Vectors in the Dry Chaco Region
}

\author{
MARÍA CARLA CECERE, ${ }^{1,2}$ GONZALO M. VAZQUEZ-PROKOPEC ${ }^{3,4}$ LEONARDO A. CEBALLOS, ${ }^{1}$ \\ SILVANA BORAGNO, ${ }^{1}$ JOAQUÍN E. ZÁRATE, ${ }^{5}$ URIEL KITRON,${ }^{3,4}$ AND RICARDO E. GÜRTLER ${ }^{1}$
}

J. Med. Entomol. 50(2): 394-403 (2013); DOI: http://dx.doi.org/10.1603/ME12109

\begin{abstract}
The effectiveness of two doses of suspension concentrate (SC) pyrethroid insecticides in suppressing peridomestic populations of Triatoma infestans (Klug) was evaluated in 28 rural communities located in Santiago del Estero province, northwestern Argentina, including 388 houses and 1,516 identified sites. Four treatments were randomly assigned to peridomiciles within each community: $5 \%$ SC $\beta$-cypermethrin at standard (S, $50 \mathrm{mg}$ active ingredient $\left.[\mathrm{AI}] / \mathrm{m}^{2}\right)$ and double dose $(2 \mathrm{~S})$, and $2.5 \% \mathrm{SC}$ deltamethrin at standard (D, $\left.25 \mathrm{mg}[\mathrm{AI}] / \mathrm{m}^{2}\right)$ and double dose (2D). Simultaneously, we assessed the effects of both pyrethroids applied at standard doses against domestic infestations. Bug infestation at the site level was assessed by timed manual collections with a dislodging agent at baseline, 13 and 21 mo postspraying (MPS). In domiciles, D and S nearly suppressed all T. infestans infestations up to 21 MPS. In peridomestic sites infested before interventions, multiple logistic regression analysis showed that site-level reinfestation at 13 MPS was significantly lower for treatment 2D $(1 \%)$ than for other treatments, whereas $2 \mathrm{~S}(6 \%), \mathrm{D}(5 \%)$, and S (14\%) did not differ significantly between them. The risk of reinfestation after spraying was significantly greater in goat or pig corrals than in other peridomestic ecotopes (in which treatments did not differ significantly), and in sites infested before interventions than in uninfested sites. The application of SC deltamethrin at double dose in goat or pig corrals may suppress T. infestans foci and achieve more sustained effects in the dry Chaco.
\end{abstract}

KEY WORDS vector control, Chaco, pyrethroid, insecticide, Chagas disease

Chagas disease affects an estimated 10-15 million people in the Americas, with $\approx 41,000$ incident cases annually and high impact on morbidity and mortality (Schofield et al. 2006, Dias 2009). A region-wide vector control program of Chagas disease, based mostly on the residual application of pyrethroid insecticides, achieved the interruption of transmission mediated by Triatoma infestans (Klug) in Uruguay, Chile, Brazil, and sections of Argentina and Paraguay (Dias et al. 2002, Silveira et al. 2002, Schofield et al. 2006). However, the elimination of T. infestans has failed in the Gran Chaco region for multiple reasons (Gürtler et al. 2007). The Gran Chaco ecoregion is a 1.1 million square kilometers semiarid plain covering large parts of northern and central Argentina, southeast Bolivia,

\footnotetext{
${ }^{1}$ Laboratorio de Eco-Epidemiología, Departamento de Ecología Genética y Evolución, Facultad de Ciencias Exactas y Naturales, Universidad de Buenos Aires, Intendente Güiraldes 2160, Ciudad Universitaria, Cl428EGA, Buenos Aires, Argentina.

${ }^{2}$ Corresponding author, e-mail: carla@ege.fcen.uba.ar.

${ }^{3}$ Department of Environmental Studies, Emory University, 400 Dowman Dr., Math and Science Center, Suite E510, Atlanta, GA 30322 .

${ }^{4}$ Fogarty International Center, 31 Center Dr., MSC 2220, National Institutes of Health, Bethesda, MD 20892-2220.

${ }^{5}$ Programa Nacional de Control de Vectores, Italia 1971, San Miguel de Tucumán, Tucumán, Argentina.
}

central and western Paraguay where Chagas disease is hyperendemic.

House compounds in the Gran Chaco are typically composed of domestic sites (human sleeping quarters) and a peridomestic area including several constructions for raising domestic animals (corrals, chicken coops), storage and other purposes (e.g., kitchen). The available evidence indicates that peridomestic structures are the weakest points of Chagas disease vector control programs in arid or semiarid areas throughout Latin America (Ronderos et al. 1980; Cecere et al. 2002, 2004, 2006a,b; Diotaiuti et al. 2000; Ramsey et al. 2003; Gürtler et al. 2004; Porcasi et al. 2006, 2007). Peridomestic ecotopes were identified as the main sources of residual T. infestans populations that increased the risk of domestic reinfestation after control interventions (Cecere et al. 2002, 2004). Heavily infested pig or goat corrals and chicken coops are suitable habitats for bug development (Gürtler et al. 2004, Ceballos et al. 2005), and particularly corrals are a sizable source of flight-dispersing adult T. infestans (Ceballos et al. 2005, Vazquez-Prokopec et al. 2006).

The residual activity of pyrethroid insecticides inside human habitations or under laboratory conditions lasts for 1-12 mo (Diotaiuti and Texeira-Pinto 1991, Ferro et al. 1995, Rojas de Arias et al. 2003), but is much shorter in peridomestic structures exposed to 


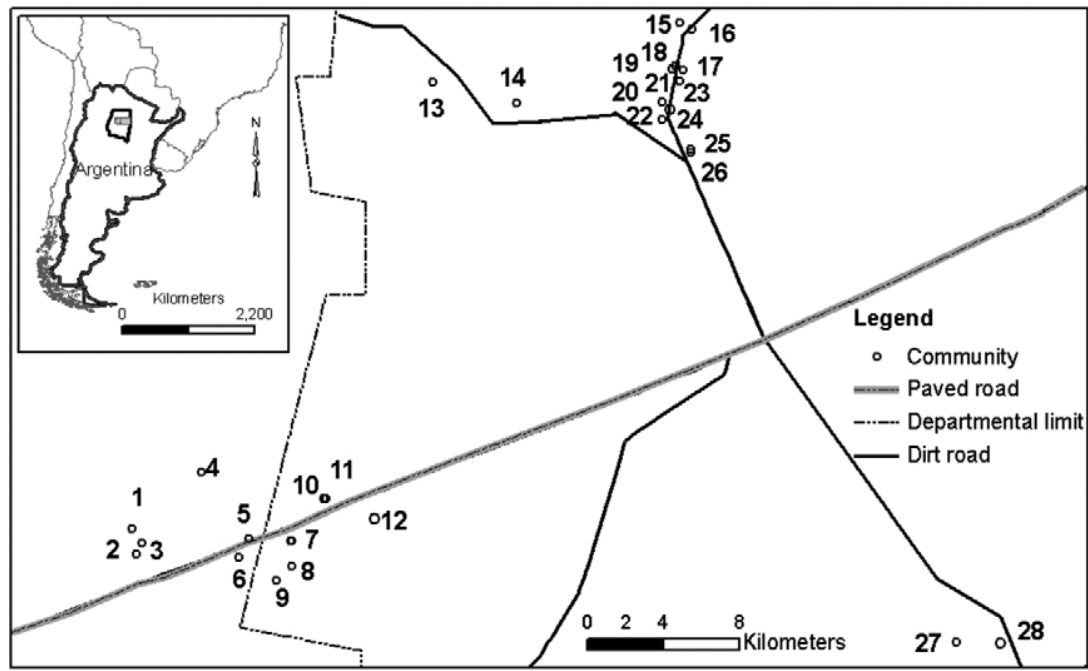

Fig. 1. Map of the study area showing the study communities (white dots). Inset shows locations of Moreno Department and Santiago del Estero Province within Argentina. The communities included were: (1) El Rincón, (2) Bella Vista, (3) San Juan, (4) San José, (5) Hornos Vittar, (6) La Ponderosa, (7) El Mercado, (8) El Fiscal, (9) Ashpa Puka, (10) Luján, (11) San Cristóbal, (12) Santa Lucía, (13) La Perla, (14) Pampa Charquita, (15) Yolanda, (16) La Blanquita, (17) Libertad-barrio, (18) Laprida, (19)Villa Isabel, (20) Libertad, (21) Santa María, (22) La Dormida, (23) Esperanza, (24) Cañada, (25) Bragado, (26) Central Dolores, (27) San Francisco, and (28) Villa Brana. The numbers represent each community.

sunlight, temperature, and other factors that cause the degradation of insecticide molecules (Roussel-Uclaf 1982, Gürtler et al. 2004). Furthermore, the lower, more variable effectiveness of pyrethroids in peridomestic areas may emerge from the presence of structures with numerous hiding places for triatomine bugs that are difficult to reach with insecticides (Diotaiuti and Texeira-Pinto 1991, Cecere et al. 2002). Despite professional community-wide spraying of pyrethroids in the absence of insecticide resistance, lack of elimination of peridomestic foci promote fast domestic reinfestation with $T$. infestans followed by new cases of human infection with T. cruzi (Gürtler et al. 1994, 2005, 2007; Cecere et al. 2004, 2006a; Porcasi et al. 2006).

Deltamethrin has been the insecticide most commonly used for the control of Triatominae since the 1980s because of its efficacy, persistence, and minimal environmental impact (Schofield 1994). The pyrethroid $\beta$-cypermethrin began to be applied in Argentina during the late 1990s (Zerba et al. 1997). Both insecticides formulated as suspension concentrate (SC) are frequently applied in current campaigns against Chagas disease vectors (Zerba 1985, 1999; Schofield 2001). A field trial conducted in the dry Argentine Chaco found that $\beta$-cypermethrin $(50 \mathrm{mg}$ active ingredient $[\mathrm{AI}] / \mathrm{m}^{2}$ ) and deltamethrin $(25 \mathrm{mg}$ $\mathrm{AI} / \mathrm{m}^{2}$ ) were similarly effective for controlling domestic and peridomestic infestations with T. infestans in 200 houses during $1 \mathrm{yr}$ (Zerba et al. 1997). The relative effectiveness of pyrethroid insecticides, formulations and doses has seldom been assessed in comparative field trials focusing on peridomestic sites. In a randomized intervention trial carried out against peridomestic T. infestans in northern Argentina, SC $\beta$-cypermethrin applied in water at $100 \mathrm{mg} \mathrm{AI} / \mathrm{m}^{2}$ (double dose) was significantly more effective than the standard dose of SC $\beta$-cypermethrin at $50 \mathrm{mg}$ $\mathrm{AI} / \mathrm{m}^{2}$ and other emulsifiable concentrate pyrethroid formulations (Cecere et al. 2006b). In the current study, we report the results of a randomized intervention trial that assessed the relative effectiveness of SC deltamethrin and SC $\beta$-cypermethrin each applied at single and double doses in peridomestic sites infested by $T$. infestans, and the effects of both pyrethroids applied at standard doses against domestic infestations. Our initial hypothesis was that both pyrethroid insecticides would achieve equivalent results conditional on dose and type of habitat (i.e., domiciles vs. peridomiciles), with larger effects in domiciles and with larger doses.

\section{Materials and Methods}

Study Area. The study was carried out in 28 rural communities in Figueroa and Moreno Departments ( $27^{\circ} 23^{\prime} \mathrm{S}, 63^{\circ} 29^{\prime} \mathrm{W}$ ), Province of Santiago del Estero, Argentina (Fig. 1). The study communities comprised 388 houses located within 1-30 km of a paved road. Only a group of communities at the center of the study area had been sprayed with deltamethrin by Argentina's National Vector Control Program (NVCP) in 2004 and was under vector surveillance and were surrounded by other communities that had not been sprayed with insecticides at the time of the current trial. All communities were located in a semiarid plain with hardwood forest undergoing intensive exploitation. Most houses were made of adobe walls and thatched roofs, with one or two adjacent bedrooms and a front veranda 5-10 $\mathrm{m}$ wide. These areas shared 
a common roof and will be referred to hereafter as domestic or domiciliary areas. The peridomestic area was separated from human habitations and consisted of a patio and 3-8 structures (e.g., storerooms, kitchens, corrals, etc.) that housed different domestic animal species. A house compound encompassed the domicile and associated peridomestic structures (i.e., peridomicile). The study area was selected for the intervention trial because it was heavily infested with T. infestans both in domestic and peridomestic sites, and recent human cases of vector-borne transmission of $T$. cruzi had been detected. The last insecticide spray of the study communities had been conducted by NVCP between 2 and 8 yr before the present trial.

Study Design. The randomized intervention trial comprised a baseline entomologic and demographic survey conducted in November 2004 or March 2005, followed by community-wide insecticide spraying between 7 March and 10 April 2005, and postspraying entomologic and demographic surveys in April and December 2006.

Baseline Survey. All 388 houses in the 28 rural communities were visited. At each house, we explained the objectives of the project and its different phases, surveyed the type and number of domestic animals, requested information on family size and insecticide use, type of building material of domestic and peridomestic structures, georeferenced each domicile, numbered each house, and posted a note of visit on the back of the front door (Cecere et al. 2006b). Four teams, each one composed of one supervisor and three skilled collectors from NVCP, searched for triatomine bugs in all domestic and peridomestic sites using timed manual collections (TMC) with a dislodging agent $(0.2 \%$ tethrametrin, Espacial 0.2, Reopen, Buenos Aires, Argentina). Two persons searched for bugs in the peridomestic sites most frequently found infested (goat or sheep corrals, pig corrals, chicken coops, storerooms, and kitchens) using one-fourth person-hour on each site, while another man searched in domiciliary sites during $30 \mathrm{~min}$ (one-half person-hour). All bugs collected were identified to species and stage (Cecere et al. 2006b).

Intervention Phase. After the baseline survey, a community-wide insecticide spraying campaign aiming at full coverage was carried out by NVCP personnel supervised by the research team. All peridomiciles found to be infested by TMC at baseline were listed alphabetically by community and then randomly assigned to one of four treatments: 1) $5 \%$ SC $\beta$-cypermethrin formulation (Sipertrin, Chemotecnica, Spegazzini, Argentina) diluted in water and applied with manual compression sprayers (Guarany, Brazil) equipped with Nell 8002 fan nozzles at concentrations of $50 \mathrm{mg} \mathrm{AI} / \mathrm{m}^{2}$ (standard dose, S) and 2) $100 \mathrm{mg}$ $\mathrm{AI} / \mathrm{m}^{2}$ (double dose, 2S); 3) 2.5\% SC deltamethrin (K-Othrina, Bayer, Munro, Argentina) applied with the same types of compression sprayer and nozzle at concentrations of $25 \mathrm{mg} \mathrm{AI} / \mathrm{m}^{2}$ (standard dose, D), and 5) $50 \mathrm{mg} \mathrm{AI} / \mathrm{m}^{2}$ (double dose, 2D). Each domicile was sprayed with a standard dose of the same type of insecticide assigned to its peridomicile. Seven teams, each one composed of one supervisor and three NVCP spray persons with $>10$ yr of experience, sprayed a total of 360 domiciles (145 with treatment $\mathrm{S}$ and 215 with D) and 304 peridomiciles (67 with treatment $S$, 68 with 2S, 102 with D and 67 with 2D) following standard procedures (http://www.msal.gov.ar/chagas/images/stories/Equipos/guia_vectorial.pdf). The fences of goat and sheep corrals, made of piled branches or shrubs, were lifted from the ground during insecticide applications to increase penetration into the matrix of vegetation and goat droppings; this nonstandard procedure was used to achieve the best possible performance for a professional insecticide spray. Before initiating spraying operations, the expected discharge volume per minute of every sprayer was verified using water; if any deviation from standard volumes was noted, the nozzle was replaced by one in proper condition. Insecticides were provided by NVCP from stocks handled and stored under standard procedures.

Postspraying Surveys. Intervention effects were assessed at 13 (April 2006) and 21 (December 2006) months postspraying (MPS). Three teams, each including one supervisor and two bug collectors, searched for triatomine bugs using $0.2 \%$ tetramethrin during 15 min (one-fourth person-hour) in each identified domicile and peridomestic site. Among 337 domestic and 1,179 peridomestic sites evaluated at baseline and treated, 318 (94\%) and 299 (89\%) domestic sites and $929(79 \%)$ and $872(79 \%)$ peridomestic sites were evaluated at 13 and 21 MPS, respectively. Peridomestic and domestic sites that could not be evaluated after spraying had been dismantled, their owners were absent, or the dirt roads were not accessible during the surveys.

During the surveillance phase, only sites infested by T. infestans were immediately resprayed selectively with $\beta$-cypermethrin at the original dose assigned to each site. Because only $\beta$-cypermethrin was available to NCVP during the postspraying phase, the effects of selective insecticide sprays of sites found infested at 13 MPS could not be assessed for each of the four treatments. Finally, all peridomestic sites found reinfested were sprayed with treatment $2 \mathrm{~S}$ at $21 \mathrm{MPS}$.

Data Analysis. The overall prevalence of infestation was estimated for domiciles and peridomiciles that were evaluated at baseline, sprayed with insecticides in 2005, and evaluated at least once after initial spraying. A peridomicile was considered infested when at least one live $T$. infestans bug was captured in any peridomestic site within that compound. A site was considered colonized when any live nymphal instar of T. infestans was captured. All sites positive by TMC after initial spraying were considered reinfested sites. The geometric mean number (GMN) of T. infestans in domiciles before initial spraying was standardized to one-fourth person-hour of capture effort in each site, on the assumption of a linear relationship between capture effort and the total number of bugs captured by TMC (Rabinovich et al. 1995).

The assessment of treatment effects only included peridomestic sites positive for $T$. infestans by TMC at 
Table 1. Overall prevalence of infestation and geometric mean no. (GMN) of $T$. infestans in domiciles and peridomiciles before and after spraying with pyrethroid insecticides

\begin{tabular}{lrrllc}
\hline \hline \multirow{2}{*}{$\begin{array}{c}\text { Months } \\
\text { postspraying }\end{array}$} & \multicolumn{2}{c}{$\begin{array}{c}\text { \% infestation } \\
\text { (no. evaluated) }\end{array}$} & & \multicolumn{2}{c}{ GMN (SD) } \\
\cline { 2 - 3 } \cline { 5 - 6 } \cline { 5 - 6 } Baseline & Domicile & Peridomicile & & Domicile & Peridomicile \\
13 & $0.5(301)$ & $61.9(267)$ & & $5(13.8)$ & $17(29.1)$ \\
21 & $0.4(275)$ & $18.9(249)$ & & $1-$ & $3(6.6)$ \\
\hline
\end{tabular}

baseline that were sprayed with insecticides in 2005 and were later evaluated for infestation at least once at 13 or 21 MPS. Treatment effects were assessed over 314 sites at 13 MPS and over 285 sites at 21 MPS. The infested sites at 13 mo. were selectively sprayed with $\beta$-cypermethrin and were not considered at $21 \mathrm{mo}$. Multiple logistic regression analysis run on Stata 10.1 (Stata Corp. 2007) was used to assess significant $(P<$ 0.05 ) effects on the binary response variable (reinfested peridomestic sites at 13 MPS) of insecticide treatment (four levels, $\mathrm{S}$ taken as the reference class) and type of ecotope (goat or pig corrals vs. other types of peridomestic ecotopes). This basic model was extended to investigate the putative effects of the $\log _{10^{-}}$ transformed baseline abundance of $T$. infestans per site as determined by TMC; previous studies showed that reinfestation postspraying increased with preintervention bug abundance (Gürtler et al. 2004, Cecere et al. 2006). The same analysis was done considering reinfestation (response variable) of goat or pig corrals separately from other peridomestic ecotopes. We used Wald's $\chi^{2}$ (with $1 \mathrm{df}$ ) to test whether the regression coefficients for each treatment differed statistically from each other. A further investigation of treatment effects on reinfestation at 13 MPS was conducted for all 929 peridomestic sites evaluated then (including infested and noninfested sites before interventions) by running a multiple logistic regression model that also included type of peridomestic ecotope and a categorical variable indexing preintervention infestation status at site and peridomicile levels (with three categories: infested sites, negative sites from an infested peridomicile, and negative sites from a negative peridomicile, the last one taken as the reference level). Poisson and negative binomial regression models were used to assess significant $(P<0.05)$ effects of insecticide treatments on the $\log _{10}$-transformed abundance of T. infestans per site at 13 MPS (response variable).

\section{Results}

The overall impact of community-wide and selective insecticide sprays on overall domestic and peridomestic infestations by $T$. infestans was striking (Table 1). Infestation in domiciles decreased 40 -fold from $40.5 \%$ at baseline to $0.7 \%$ at 13 MPS, and after selective sprays reached $0.4 \%$ at 21 MPS. In peridomiciles, however, overall infestation was reduced much less than in domiciles from 61.9 to $11.0 \%$ at 13 MPS, rising to $18.9 \%$ at 21 MPS. Only three domiciles were colonized after interventions, whereas 61 and $72 \%$ of infested peridomiciles were colonized at 13 and 21 MPS, respectively. GMN of T. infestans per peridomicile decreased sharply from 17 bugs at baseline to two and three bugs at 13 and 21 MPS, respectively, whereas in domiciles GMNs were 5, 7, and 1 bug per unit of capture effort per site.

For all sites evaluated at least once after intervention, every peridomestic ecotope showed substantially higher infestation prevalence and abundance of $T$. infestans than domiciles after initial insecticide spraying (Fig. 2). Goat corrals had the highest infestation before $(58 \%)$ and after initial insecticide spraying (7$15 \%$ ), followed by pig corrals (38 and $4-8 \%$, respectively). Infestation of storerooms, chicken coops, and kitchens ranged from 29 to $45 \%$ before initial spraying, and from 0 to $4 \%$ after spraying. Goat or pig corrals represented $90 \%$ of peridomestic sites with a persistent infestation (i.e., both times positive) between 0 and 13 MPS. Among all initially infested peridomestic sites evaluated after interventions, goat or pig corrals contributed the most to the prevalence of infestation before $(63 \%, 210 / 331)$ and after $(89 \%, 47 / 53)$ initial spraying. Of 1,348 sites evaluated before initial spraying and at least once thereafter, only $1 \%(3 / 327)$ of domestic sites and $8 \%(84 / 1021)$ of peridomestic sites were reinfested after spraying.

Figure 3 shows the effects of insecticidal treatments on reinfestation of peridomestic sites infested at baseline according to type of ecotope and time after intervention. At the aggregate level (i.e., disregarding ecotope effects), treatment 2D achieved the lowest reinfestation at 13 MPS (1\%) followed by D (5\%), 2 S $(6 \%)$, and $\mathrm{S}(14 \%)\left(\chi^{2}=10.87 ; \mathrm{df}=3 ; P<0.05\right)$. Colonization ranged from 0 to $1 \%$ in sites treated with $\mathrm{D}$ or $2 \mathrm{D}$ and from 5 to $8 \%$ in those treated with $\mathrm{S}$ or $2 \mathrm{~S}$, respectively. Multiple logistic regression analysis showed that the relative odds of reinfestation at 13 MPS adjusted for type of ecotope was significantly lower for $2 \mathrm{D}$ (Odds Ratio $[\mathrm{OR}]=0.08 ; 95 \% \mathrm{CI}=$ $0.01-0.64 ; P=0.02)$ than for $\mathrm{S}$, whereas treatments $\mathrm{D}$ $(\mathrm{OR}=0.35 ; \mathrm{CI}=0.10-1.18 ; P=0.09)$ and $2 \mathrm{~S}(\mathrm{OR}=$ 0.40 ; $\mathrm{CI}=0.13-1.25 ; P=0.11)$ did not differ significantly from $\mathrm{S}$. We detected statistically significant differences between treatments $2 \mathrm{D}$ and $2 \mathrm{~S}\left(\chi^{2}=6.95\right.$; $P=0.03)$ and between $2 \mathrm{D}$ and $\mathrm{D}\left(\chi^{2}=7.31 ; P=0.02\right)$, whereas no such differences occurred between $2 S$ and $\mathrm{D}\left(\chi^{2}=4.02 ; P=0.13\right)$. Reinfestation of goat or pig corrals was significantly higher than for other peridomestic ecotopes $(\mathrm{OR}=5.20$; $\mathrm{CI}=1.17-23.08 ; P=$ $0.03)$. Addition of the baseline abundance of T. infestans per site did not increase the fit of the model to the data. At 21 MPS, differences between treatments were not statistically significant from $\mathrm{S}(2 \mathrm{D}: \mathrm{OR}=0.74, \mathrm{CI}=$ $0.26-2.06 ; \mathrm{D}: \mathrm{OR}=0.87, \mathrm{CI}=0.32-2.36 ; 2 \mathrm{~S}: \mathrm{OR}=0.31$, $\mathrm{CI}=0.09-1.08)$ or between each of them. Poisson and negative binomial regressions analysis did not reveal significant treatment effects on the relative abundance of bugs per site at 13 MPS when adjusted for type of ecotope, and the interaction between treatment and ecotope (Fig. 3). 


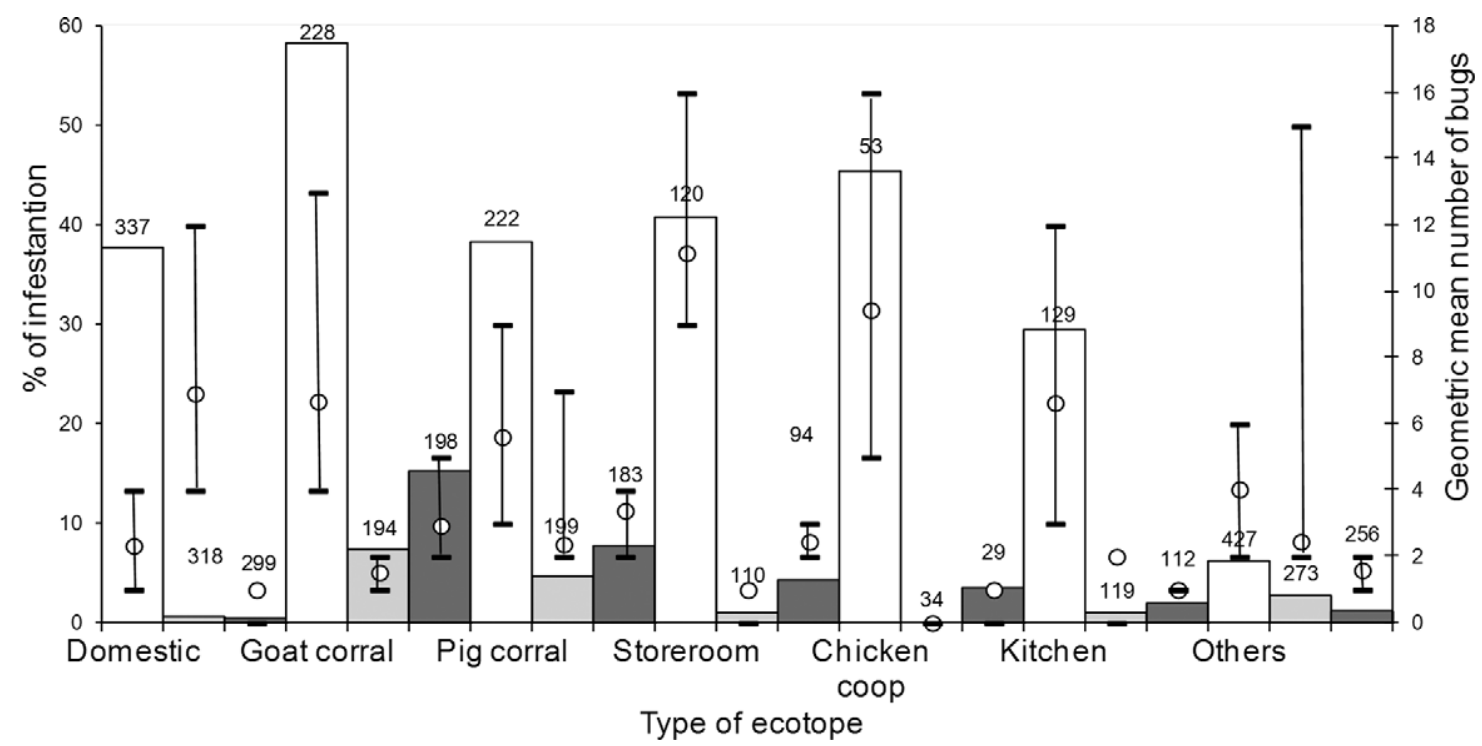

Fig. 2. Prevalence of infestation and geometric mean number (GMN) of T. infestans per site for each type of ecotope before and after community-wide insecticide spraying at 13 and 21 mo postspraying (MPS). The numbers of sites inspected for infestation are on top of histogram bars. Whiskers represent \pm 1 SD of log-transformed data.

When stratified by type of peridomestic ecotope, treatment effects on reinfestation at 13 MPS differed to some extent between ecotopes (Fig. 3A,B). For ecotopes other than corrals (i.e., storerooms, kitchens, chicken coops, and others), reinfestation varied between $0 \%$ for $\mathrm{D}$ and $2 \mathrm{D}$ to $3-5 \%$ for $\mathrm{S}$ and $2 \mathrm{~S}\left(\chi^{2}=2.52\right.$; $\mathrm{df}=3 ; P=0.47)$, with only two sites found infested (Fig. 3A). In goat or pig corrals, however, reinfestation at 13 MPS was significantly lower in sites treated with $2 \mathrm{D}(\mathrm{OR}=0.09 ; \mathrm{CI}=0.01-0.73 ; P<0.024)$ than with $\mathrm{S}$, whereas treatments $\mathrm{D}(\mathrm{OR}=0.40 ; \mathrm{CI}=0.12-1.41)$ and $2 \mathrm{~S}(\mathrm{OR}=0.36 ; \mathrm{CI}=0.10-1.24)$ did not differ significantly from S (Fig. 3B). Reinfestation differed significantly between treatments $2 \mathrm{D}$ and $\mathrm{D}\left(\chi^{2}=6.05\right.$; $P=0.04)$ or between $2 \mathrm{D}$ and $2 \mathrm{~S}\left(\chi^{2}=6.51 ; P=0.04\right)$; treatments $\mathrm{D}$ and $2 \mathrm{~S}$ did not differ significantly $(P>$ $0.17)$. Colonization ranged from 0 to $2 \%$ in sites treated with $\mathrm{D}$ or $2 \mathrm{D}$ and between 6 and $12 \%$ in those treated with $\mathrm{S}$ or $2 \mathrm{~S}$.

Figure 4 shows treatment effects on reinfestation of all 929 peridomestic sites treated and reevaluated at 13 MPS according to type of ecotope and the preintervention status of infestation at site and peridomicile levels. For all peridomestic sites, the adjusted relative odds of reinfestation was significantly lower for $2 \mathrm{D}$ $(\mathrm{OR}=0.18$; $\mathrm{CI}=0.05-0.64 ; P=0.01)$ than for $\mathrm{S}$, whereas treatments $\mathrm{D}(\mathrm{OR}=0.44$; $\mathrm{CI}=0.17-1.14)$ and $2 \mathrm{~S}(\mathrm{OR}=0.56 ; \mathrm{CI}=0.23-1.37)$ did not differ significantly from $\mathrm{S}$. Treatment $2 \mathrm{D}$ differed significantly from $2 \mathrm{~S}\left(\chi^{2}=7.28 ; P<0.02\right)$ and $\mathrm{D}\left(\chi^{2}=8.03\right.$; $P=0.02)$, whereas $\mathrm{D}$ and $2 \mathrm{~S} \operatorname{did} \operatorname{not}\left(\chi^{2}=3.31 ; P=\right.$ $0.19)$. Reinfestation of pig or goat corrals was significantly higher than for other peridomestic ecotopes $(\mathrm{OR}=2.85 ; \mathrm{CI}=1.23-6.60 ; P=0.01)$. Relative to negative sites that belonged to a negative peridomicile, reinfestation was significantly higher in sites in- fested before interventions $(\mathrm{OR}=4.26$; $\mathrm{CI}=1.22$ 14.77; $P=0.02)$ but not in negative sites from an infested peridomicile $(\mathrm{OR}=2.38 ; \mathrm{CI}=0.63-9.04 ; P=$ 0.2 ). For ecotopes other than corrals, reinfestation was low and differences between treatments were not statistically significant from S $(2 \mathrm{D}$ : $\mathrm{OR}=0.75, \mathrm{CI}=$ $0.10-5.45 ; \mathrm{D}: \mathrm{OR}=0.37, \mathrm{CI}=0.03-4.10 ; 2 \mathrm{~S}: \mathrm{OR}=1.71$, $\mathrm{CI}=0.31-9.55)$, nor were they modified by the preintervention status of infestation at site and peridomicile levels (Fig. 4A). For goat or pig corrals, the ranking of treatment effectiveness up to 13 MPS and statistical results were qualitatively the same as for all peridomestic ecotopes (Fig. 4B).

Both S and D treatments suppressed domestic infestations almost completely. Between baseline and 13 MPS, domestic infestations fell from $37 \%(74 / 198)$ to $0.5 \%(1 / 185)$ for treatment $\mathrm{D}$, and from $38 \%(53 / 139)$ to $0.8 \%(1 / 133)$ for $\mathrm{S}$ (Fisher test; $P=1.0)$. Only one domicile was found reinfested at 21 MPS. All domestic sites negative at baseline and sprayed with pyrethroids remained negative up to 21 MPS.

\section{Discussion}

Our trial documents that the effectiveness of pyrethroid-based treatments differed substantially between domestic and peridomestic ecotopes; between goat or pig corrals and other peridomestic ecotopes, and between pyrethroid insecticides and doses in rural areas of the dry Chaco. SC deltamethrin applied with manual compression sprayers at $2 \mathrm{D}$ nearly suppressed peridomestic infestations with T. infestans up to 13 MPS and produced significantly enhanced effects in goat or pig corrals. In contrast, both community-wide treatments $\mathrm{S}$ and $\mathrm{D}$ suppressed domestic infestations almost completely up to 21 MPS, in agreement with 

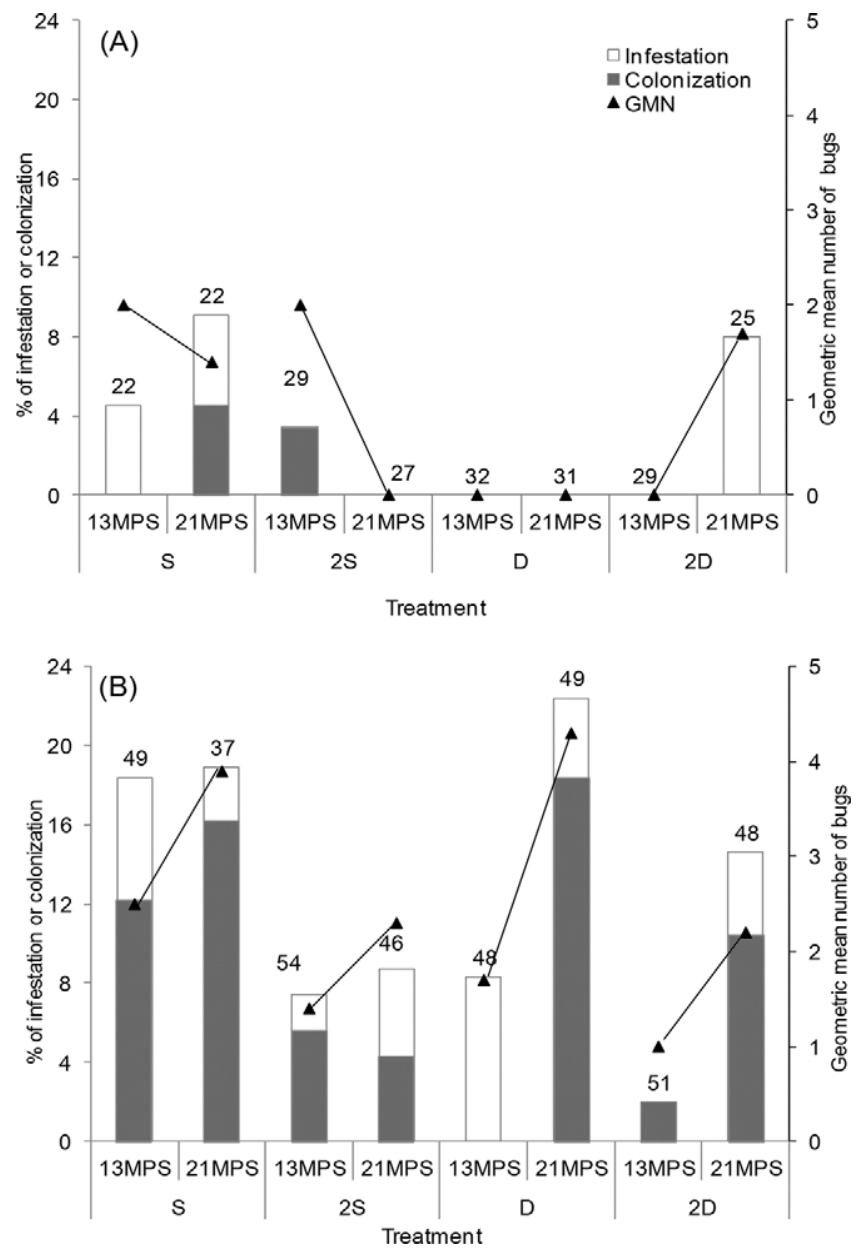

Fig. 3. Percentage of infestation, colonization, and GMN of T. infestans per site at 13 and 21 MPS according to type of treatment (S, 2S, D, and 2D) in (A) storerooms, kitchens, chicken coops, and other sites; and (B) only goat or pig corrals. Figure includes sites infested at baseline that were treated and reevaluated at 13 or 21 MPS. Sites that were infested sites at 13 mo. were selectively sprayed with $\beta$-cypermethrin and were not considered at 21 MPS. The numbers of sites inspected for infestation are on top of histogram bars.

earlier studies (Zerba et al. 1997, Cecere et al. 2002). Moreover, differential treatment effects in peridomestic ecotopes other than corrals were slight and nonsignificant. In general, storerooms and kitchens were built in a similar manner as domestic sites, and thus pyrethroid molecules there were less affected by exposure to sunlight, dust, or rain than in other open structures such as corrals.

An earlier intervention trial that assessed the effectiveness of $\mathrm{S}$ and $2 \mathrm{~S}$ on infested peridomestic sites showed that $2 \mathrm{~S}$ apparently suppressed peridomestic infestations at 5 MPS whereas treatment effects did not differ at 12 MPS (Cecere et al. 2006b). The current trial corroborates that standard doses do not suppress peridomestic infestations at 13 MPS; extends these findings to SC deltamethrin with a standard dose, and more generally, emphasizes the challenge of suppressing $T$. infestans populations from peridomestic ecotopes.
Although the differences between treatments 2D and the rest were statistically significant, the strength of the evidence was reasonable though not very strong $(0.02<P<0.03)$ and the absolute differences in the mean size of the effects were modest within pyrethroid insecticides (e.g., 2D and D effects differed by $4 \%)$. An earlier trial also showed modest, nonsignificant differences between $\mathrm{D}$ and $\mathrm{S}$ in peridomiciles that ran in the same direction as in the current trial (Zerba et al. 1997). Whether such differences in effectiveness are meaningful from a practical point of view is closely related to the ultimate goal of the vector control program (i.e., bug elimination vs. control, interruption of parasite transmission) and a cost-effectiveness analysis (see below). In the dry Chaco region, most of the human transmission of T. cruzi mediated by $T$. infestans occurs in domiciles, and vector infection is higher in domiciles than in peridomestic areas before and after community-wide insecticide spraying 

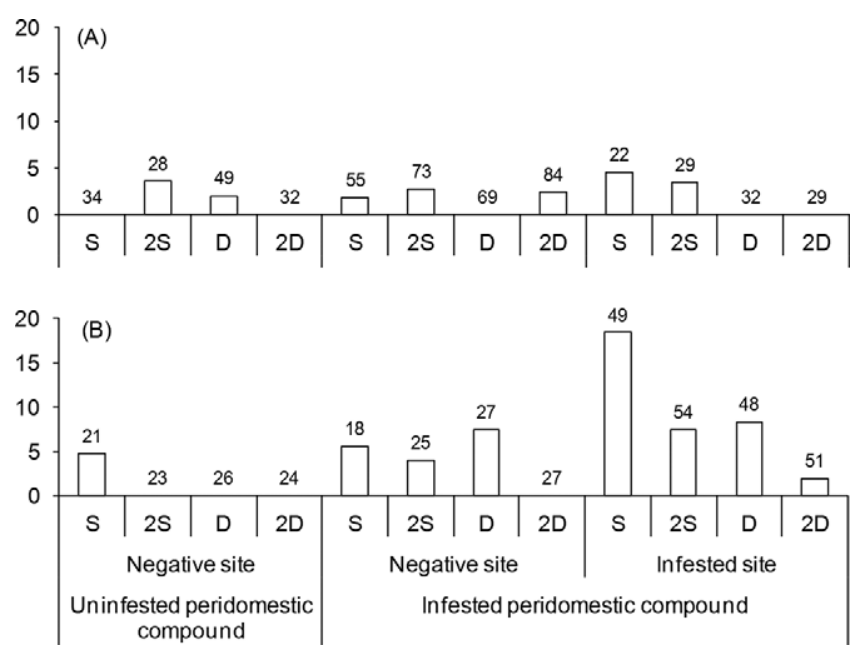

Fig. 4. Percentage of infestation with $T$. infestans at 13 MPS according to type of treatment and whether they belonged to an infested or noninfested peridomicile before interventions in (A) storerooms, kitchens, chicken coops, and other similar peridomestic sites; and (B) only goat or pig corrals. Figure includes all sites evaluated at baseline that were treated and reevaluated at 13 or 21 MPS. Sites that were infested sites at 13 mo. were selectively sprayed with $\beta$-cypermethrin and were not considered at 21 MPS. The numbers of sites inspected for infestation are on top of histogram bars.

(Gürtler et al. 2007). If the ultimate goal of the control program is vector elimination from high-risk areas, in the absence of surveillance and effective response a single house or peridomestic structure left infested could lead to reinfestation of the whole community in 3-5 $\mathrm{yr}$ and the appearance of new human cases of $T$. cruzi during such period (Gürtler et al. 2005). An exclusive focus on the interior of domestic sites for immediate interruption of disease incidence may achieve this goal at the expense of recurrent insecticide sprays to prevent bug invasion from peridomestic sources. Past experience shows that these efforts have not been sustainable in high-risk rural areas in the Chaco.

We were most interested in assessing whether the study treatments were able to suppress preintervention infestations in a context of minimal environmental changes and reduced bug invasion from elsewhere. In the current trial, treatment effects were better measured by the outcome at 13 rather than at 21 MPS mainly because: 1 ) the residual effects of pyrethroids in peridomestic habitats of the dry Chaco during summer only last for a few days or weeks-a period not long enough to affect $T$. infestans eggs by the time they hatch (Gürtler et al. 2004), and 2) the time needed for build-up of bug population numbers to surpass the detectability threshold of TMC. Producing a new generation of adult $T$. infestans from eggs may take between 6 and 12 mo depending on temperature and host availability (Cecere et al. 2003). In a context of fast reinfestation after interventions as in Santiago del Estero, infestation at 21 MPS represents a rather advanced stage of the process of bug propagation from various sources despite of selective treatments after community-wide insecticide spraying. Consistent with these views, treatment effects in peridomestic sites were not significantly different among all tested insecticides and doses at 21 MPS.

Infestations detected for the first time at 13 and 21 MPS were the outcome of several processes that most likely differed in their relative magnitude: low-density infestations missed at baseline because of the limited sensitivity of timed-manual collections with a dislodging aerosol (Gürtler et al. 2001, Abad-Franch et al. 2011); local residual foci after initial insecticide spraying, and recent bug invasions from other foci. Pyrethroid resistance did not play any role in this trial because local $T$. infestans populations in 2004 showed no evidence of diminished susceptibility to pyrethroids in diagnostic dose assays (M.I.P., unpublished results), nor had they been detected in Santiago del Estero province yet (Picollo 2001).

The sites found positive by TMC after initial spraying were denominated "reinfested sites" although bugs collected after interventions might have been bugs that survived treatment (i.e., not a new infestation) or that might have migrated into the trial site after intervention (Schofield 2001). The most likely sources of postspraying infestations in sites that had been infested at baseline were triatomine bugs that survived insecticide treatment (i.e., residual foci), as in previous field trials in the dry Chaco (Gürtler et al. 2004, Cecere et al. 2006b). In general, peridomestic sites infested before interventions experienced a higher risk of becoming reinfested at 13 MPS than negative sites (regardless of whether the latter belonged to a peridomicile that had been infested before interventions or not). This is an important piece of evidence suggesting that the foci detected after interventions were most likely residual foci (i.e., not true reinfestations). Other types of evidence that may be used for this purpose is the relative stage structure of bug 
populations before and early after interventions (Gurevitz et al. 2013), microsatellite markers and wing morphometry (e.g., Pérez de Rosas et al. 2007, Ceballos et al. 2011).

Despite the inferred prime role of persistent residual foci, active bug invasions from nearby residual foci may perhaps explain in part the infestation of negative sites before initial interventions. The 13-MPS survey was conducted shortly after summer, when bug populations and adult insects are more abundant and more dispersive flights occur (Ceballos et al. 2005, VazquezProkopec et al. 2006). Additional bug sources external to the study communities were kept to a minimum through extended coverage of neighboring rural areas. Although low-density sylvatic foci of T. infestans were detected locally (Ceballos et al. 2011), they were rare and unlikely to explain the rather large reinfestation rates recorded, especially of sites that had been infested before interventions.

Domestic and peridomestic infestations with T. infestans after application of a standard dose of SC pyrethroid insecticides increased with the preintervention abundance of bugs per site in several field trials (Gürtler et al. 1994, 2004; Cecere et al. 2002), but no significant association was found when a double dose was applied (Cecere et al. 2006b). In the current trial, reinfestation up to 13 MPS was positively and significantly associated with the preintervention infestation status at site level, but not with preintervention bug abundance. The fact that negative sites located in infested peridomiciles tended to have an increased (though not statistically significant) probability of becoming reinfested after initial interventions is probably explained by the occurrence of spatial aggregation of infested sites between and within house compounds at a wide range of distances (Cecere et al. 2006a, Levy et al. 2008) and by the limited detectability of TMC.

Our trial further corroborates that goat or pig corrals are key ecotopes for T. infestans and play a major role as residual foci that drive the subsequent reinfestation process in the dry Chaco (Gürtler et al. 2004; Cecere et al. 2002, 2006b). These ecotopes are mainly characterized by frequent infestation and large bug abundance before and after residual insecticide spraying; precarious construction with piled thorny shrubs or branches and wooden posts or planks that provide plenty refuges for bugs; high exposure to weather agents that undermine pyrethroid effects, and bug populations with a variable nutritional status that promotes flight dispersal under appropriate conditions (Ceballos et al. 2005, Vazquez-Prokopec et al. 2006). Although improved insecticide regimes may cope with infestations in goat or pig corrals, replacing current construction patterns with wire fences and roofs that minimize refuges for bugs would exert more sustainable effects on local infestations and minimize the use of insecticides (Ronderos et al. 1980; D.E.G., unpublished results).

Among the main limitations of our study is the lack of assessment of infestations at an earlier time point after initial interventions, and use of only one pyrethroid insecticide to treat reinfested foci detected at
13 MPS rather than repeating the same initial treatment at each reinfested site. The sole use of TMC to detect infestations suggests that the actual occurrences of bug infestations before and after interventions were underestimated, especially after interventions when bug abundance is very low. Future trials should also consider testing the bugs for T. cruzi infections before and after interventions, and estimate the impact of interventions on parasite transmission; both aspects were beyond our operational capacity in this trial. Major strengths of our trial were a relatively large sample of key peridomestic ecotopes, randomization of treatments within rural communities, and blind assessment procedures. The underlying rationale was to consider each infested site as a distinct population of $T$. infestans, rather than considering the entire house or peridomicile (that comprise different types of ecotopes with different infestation status) as the experimental unit. Thus, the effectiveness of an insecticide application in suppressing bugs can be assessed for specific sites; peridomestic ecotopes with infestations that are harder to eliminate may be identified, and the heterogeneity of infestation risk by type of ecotope may be accounted for.

Our study documented a relatively fast reinfestation of peridomestic sites despite achieving full spray coverage with both pyrethroids in use and a larger total amount of insecticide applied than in routine control operations using standard doses. House infestations with $T$. infestans were mainly detected in peridomestic structures during the first year after community-wide spraying with pyrethroid insecticides in several studies (Dujardin et al. 1996; Cecere et al. 2002; Guillén et al. 1997; Zerba et al. 1997; Gürtler et al. 2004; Porcasi et al. 2006, 2007), including other triatomine bug species in arid and semiarid areas of Brazil and Mexico (Diotaiuti et al. 2000, Ramsey et al. 2003). In the Gran Chaco, community-wide residual spraying of different SC pyrethroid insecticides at standard dose have not reached the expected levels of effectiveness against $T$. infestans in peridomestic areas (Silveira 2002, Gürtler et al. 2007). Therefore, an improved, targeted, vector control strategy that accounts for heterogeneities in infestation and treatment effectiveness is needed.

To reach this goal vector control programs should have the option and ability to select and use the chemical they need for proper control in time and space. An evidence of this limitation was the lack of one pyrethroid insecticide after initial interventions, which determined the use of the only insecticide available for selective sprays. The same limitations hold true for standard Chagas vector control programs in many other countries. The complex administrative process of purchasing insecticides, mostly based on competitive prices, determines large variations in the availability, timing and type of pyrethroid insecticide purchased from year to year.

The evidence obtained in this trial supports the application of a double dose of SC deltamethrin in corrals and other key peridomestic ecotopes that are more likely to harbor persistent populations of $T$. infestans, especially if rural communities are not easily 
accessible and the need of recurrent visits and treatments is anticipated. However, a cost-effectiveness analysis of a vector control strategy targeting key peridomestic structures with double-dose pyrethroids during the attack phase versus the standard approach is needed before issuing a final recommendation. As a preliminary calculation, in a typical attack phase of a vertically structured vector control program against $T$. infestans in Santiago del Estero, the relative cost of transportation, vehicle fixes and per diems of the spray teams almost tripled the total cost in insecticides when two rounds of residual spraying with pyrethroids were conducted (Vazquez-Prokopec et al. 2009). Rather than revisiting houses for a second treatment round with a standard dose, intensified residual spraying of key peridomestic structures with a double dose of pyrethroids may be more cost-effective in remote rural communities. Potential savings may be compared with the gains obtained from using a double dose in key ecotopes. Suppression of peridomestic bug populations in key ecotopes will reduce residual sources of bugs, prevent rapid domestic reinfestation, eliminate the need for repeated community-wide spraying with insecticides, and ultimately minimize the risk of T. cruzi transmission.

\section{Acknowledgments}

In memory of Joaquín Zárate. We thank the staff of the National Vector Control Program at Tucumán and Córdoba, Diego Glaser, Leonardo Lanati, Silvana Ferreyra, and Mariana Carro for providing active support during fieldwork and data entry; residents of the communities for their participation; Padre Sergio, Sara, and Tuki families of Bandera Bajada, Moyano and Citati families of Amamá, and the families from Libertad for field accommodation. This study was supported by awards from Fundación Bunge y Born (Argentina) to M.C.C., the National Institutes of Health/National Science Foundation Ecology of Infectious Disease program award R01TW05836 funded by the Fogarty International Center and the National Institute of Environmental Health Sciences to U.K. and R.E.G, and the University of Buenos Aires to R.E.G. The participation of R.E.G. was also supported by United Nations Development Programme/World Bank/ World Health Organization/Training in Tropical Diseases (grant A70596) and International Development Research Centre (grant 103696-009). M.C.C. and R.E.G. are members of Consejo Nacional de Investigaciones Científicas Y Técnicas (CONICET) Researcher's Career.

\section{References Cited}

Abad-Franch, F., M. C. Vega, M. S. Rolón, W. S. Santos, and A. Rojas de Arias. 2011. Community participation in Chagas disease vector surveillance: systematic review. PLoS Negl. Trop. Dis. 5: e1207.

Ceballos, L. A., G. M. Vazquez-Prokopec, M. C. Cecere, and R. E. Gürtler. 2005. Feeding rates, nutritional status and flight dispersal potential of peridomestic populations of Triatoma infestans in rural northwestern Argentina. Acta Trop. 95: 149-159.

Ceballos, L. A., R. V. Piccinali, P. L. Marcet, G. M. VazquezProkopec, M. V. Cardinal, J. Schachter-Broide, J. P. Dujardin, E. M. Dotson, U. Kitron, and R. E. Gürtler. 2011. Hidden sylvatic foci of the main vector of Chagas disease
Triatoma infestans: threats to the vector elimination campaign? PLoS Negl. Trop. Dis. 5: e1349.

Cecere, M. C., R. E. Gürtler, D. M. Canale, R. Chuit, and J. E. Cohen. 2002. Effects of partial housing improvement and insecticide spraying on the reinfestation dynamics of Triatoma infestans in rural northwestern Argentina. Acta Trop. 84: 101-116.

Cecere, M. C., D. M. Canale, and R. E. Gürtler. 2003. Effects of refuge availability on the population dynamics of Triatoma infestans in central Argentina. J. Appl. Ecol. 41: $742-756$.

Cecere, M. C., G. M. Vázquez-Prokopec, R. E. Gürtler, and U. Kitron. 2004. Spatio-temporal analysis of reinfestation by Triatoma infestans (Hemiptera:Reduviidae) following insecticide spraying in a rural community in northwestern Argentina. Am. J. Trop. Med. Hyg. 71: 803810.

Cecere, M. C., G. M. Vazquez-Prokopec, R. E. Gürtler, and U. Kitron. 2006a. Reinfestation sources for Chagas disease vector, Triatoma infestans, Argentina. Emerg. Inf. Dis. 12: 1096-1102.

Cecere, M. C., G. M. Vazquez-Prokopec, L. A. Ceballos, J. M. Gurevitz, J. E. Zárate, M. Zaidenberg, U. Kitron, and R. E. Gürtler. 2006b. Comparative trial of the effectiveness of pyrethroid insecticides against peridomestic populations of Triatoma infestans in northwestern Argentina. J. Med. Entomol. 43: 902-909.

Dias, J.C.P., A. C. Silveira, and C. J. Schofield. 2002. The impact of Chagas disease control in Latin America: a review. Mem. Inst. Oswaldo Cruz 97: 603-612.

Dias, J.C.P. 2009. Elimination of Chagas disease transmission: perspectives. Mem. Inst. Oswaldo Cruz 104(Suppl. I) : $41-45$.

Diotaiuti, L., and C. Texeira-Pinto. 1991. Susceptibilidade biológica do Triatoma sordida e Triatoma infestans a deltametrina e lambdacyhalotrina em condições de campo. Rev. Soc. Bras. Med. Trop. 24: 151-155.

Diotaiuti, L., O. Faria Filho, F.C.F. Carneiro, J.C.P. Dias, H.H.R. Pires, and C. J. Schofield. 2000. Aspectos operacionais do controle do Triatoma brasiliensis. Cad. Saúde Pública. 16: 7-14.

Dujardin, J. P., L. Cardozo, and C. J. Schofield. 1996. Genetic analysis of Triatoma infestans following insecticidal control interventions in central Bolivia. Acta Trop. 61: 263-266.

Ferro, E. A., A. R. Arias, M. E. Ferreira, L. C. Simancas, L. S. Rios, and J. M. Rosner. 1995. Residual effects of lambdacyhalothrin on Triatoma infestans. Mem. Inst. Oswaldo Cruz 90: 415-419.

Guillén, G., R. Díaz, A. Jemio, J. A. Cassab, C. Teixeira Pinto, and C. J. Schofield. 1997. Chagas disease vector control in Tupiza, southern Bolivia. Mem. Inst. Oswaldo Cruz 92: $1-8$.

Gurevitz, J. M., M. S. Gaspe, G. F. Enriquez, C. Vassena, J. A. Alvarado-Otegui, Y. M. Provecho, G. Mougabure-Cueto, M. I. Picollo, U. Kitron, and R. E. Gürtler. 2013. Unexpected failure to control Chagas disease vectors with pyrethroid spraying in northern Argentina. J. Med. Entomol. (in press).

Gürtler, R. E., R. M. Petersen, M. C. Cecere, N. J. Schweigmann, R. Chuit, and J. M. Gualtieri. 1994. Chagas disease in north-west Argentina: risk of domestic reinfestation by Triatoma infestans after a single community wide application of deltamethrin. Trans. R. Soc. Trop. Med. Hyg. 88: 27-30.

Gürtler, R. E., G. M. Vazquez Prokopec, L. A. Ceballos, C. Lund Petersen, and O. D. Salomon. 2001. Comparison between two artificial shelter units and timed manual 
collections for detecting peridomestic Triatoma infestans (Hemiptera: Reduviidae) in rural northwestern Argentina. J. Med. Entomol. 38: 429-436.

Gürtler, R. E., D. M. Canale, C. Spillmann, R. Stariolo, O. D. Salomón, S. Blanco, and E. L. Segura. 2004. Effectiveness of residual spraying with deltamethrin and permethrin on peridomestic populations of Triatoma infestans in rural western Argentina: a district-wide randomized trial. Bull. W.H.O. 82: 196-205.

Gürtler, R. E., M. C. Cecere, M. A. Lauricella, R. M. Petersen, D. M. Canale, M. B. Castañera, R. Chuit, E. L. Segura, and J. E. Cohen. 2005. Incidence of Trypanosoma cruzi infection among children following domestic reinfestation after insecticide spraying in rural northwestern Argentina. Am. J. Trop. Med. Hyg. 73: 95-103.

Gürtler, R. E., U. Kitron, M. C. Cecere, E. L. Segura, and J. E. Cohen. 2007. Sustainable vector control and management of Chagas disease in the Gran Chaco, Argentina. Proc. Nat. Acad. Sci. U.S.A. 141: 16194-16199.

Levy, M. Z., V. R. Quíspe-Machaca, J. L. Ylla-Velasquez, L. A. Waller, J. M. Richards, B. Rath, K. Borrini-Mayori, J. G. del Carpio, E. Cordova-Benzaquen, F. E. McKenzie, et al. 2008. Impregnated netting slows infestation by Triatoma infestans. Am. J. Trop. Med. Hyg. 79: 528-34.

Pérez de Rosas, A. R., E. L. Segura, and B. A. García. 2007. Microsatellite analysis of genetic structure in natural Triatoma infestans (Hemiptera: Reduviidae) populations from Argentina: its implication in assessing the effectiveness of Chagas' disease vector control programmes. Mol. Ecol. 16: 1401-1412.

Piccollo, M. I. 2001. Avances en el monitoreo de resistencia en Triatominos y perspectivas futures, pp. 13-20. In F. M. Sano (ed.), Monitoreo de la Resistencia a Insecticidas en Triatominos en América Latina. Fundación Mundo Sano, Buenos Aires, Argentina.

Porcasi, X., S. S. Catala, H. Hrellac, M. C. Scavuzzo, and D. E. Gorla. 2006. Infestation of rural houses by Triatoma infestans (Hemiptera: Reduviidae) in southern area of Gran Chaco in Argentina. J. Med. Entomol. 43: 1060-1067.

Porcasi, X., H. Hrellac, S. Catalá, M. Moreno, L. Abrahan, L. Hernandez, and D. E. Gorla. 2007. Infestation of rural houses by Triatoma infestans in the region of Los Llanos (LaRioja, Argentina). Mem. Inst. Oswaldo Cruz 102: 6368.

Rabinovich, J. E., R. E. Gürtler, J. Leal., and D. F. Piñero. 1995. Density estimates of the domestic vector of Chagas disease, Rhodnius prolixus Stahl (Hemiptera, Reduviidae), in rural houses in Venezuela. Bull. W.H.O. 73: 347357.

Ramsey, J. M., A. Cruz-Celis, L. Salgado, L. Espinosa, R. Ordoñez, R. Lopez, and C. J. Schofield. 2003. Efficacy of pyrethoid insecticides against domestic and peridomestic populations of Triatoma pallidipennis and Triatoma bar- beri (Reduviidae: Triatominae) vectors of Chagas' disease in Mexico. J. Med. Entomol. 40: 912-920.

Rojas de Arias, A., M. J. Lehane, C. J. Schofield, and A Fournet. 2003. Comparative evaluation of pyrethroid insecticide formulations against Triatoma infestans (Klug): residual efficacy on four substrates. Mem. Inst. Oswaldo Cruz 98: 975-980.

Ronderos, R. A., J. A. Schnack, and R. A. Mauri. 1980. Resultados preliminares respecto de la ecología de Triatoma infestans (Klug) y especies congenericas con referencia especial a poblaciones peridomiciliarias. Medicina 40 (Suppl. 1): 187-196.

Roussel Uclaf. 1982. Deltamethrin, pp. 268-271. l'Imprimerie Aubanel Press, Avignon, France.

Schofield, C. J. 2001. Field testing and evaluation of insecticides for indoor residual spraying against domestic vectors of Chagas disease. World Health Organization, Geneva, Switzerland. (WHO/CDS/WHOPES/GCDPP/ 2001.1).

Schofield, C. J., J. Jannin, and R. Salvatella. 2006. The future of Chagas disease control. Trends Parasitol. 22: 583-588.

Silveira, A. C. 2002. El control de la enfermedad de Chagas en los países del Cono Sur de América. Historia de una iniciativa internacional, 1991-2001, pp. 15-43. In A. C. Silveira, A. Rojas de Arias, G. Guillén, G. Russomando, H. Schenone, J.C.P. Dias, J. Valdés Padilla, M. Lorca, and R. Salvatella (eds.). Facultad de Medicina do Triangulo Mineiro, Pan American Health Organization, Uberaba, Brasil.

StataCorp. 2008. Stata statistical software, release 10.1. Stata Corporation, College Station, TX.

Vazquez-Prokopec, G. M., L. A. Ceballos, P. L. Marcet, M. C. Cecere, M. V. Cardinal, U. Kitron, and R. E. Gürtler. 2006. Seasonal variations in active dispersal of natural populations of Triatoma infestans in rural north-western Argentina. Med. Vet. Entomol. 20: 1-6.

Vazquez-Prokopec, G. M., C. Spillmann, M. Zaidenberg, U. Kitron, and R. E. Gürtler. 2009. Cost-effectiveness of Chagas disease vector control strategies in Northwestern Argentina. PLoS Negl. Trop. Dis. 3: e363.

Zerba, E. N. 1985. Global collaboration for development of pesticides for public health (GCDPP). Past and Present of Chagas Vector Control and Future Needs. World Health Organization. Communicable Diseases. WHO Pesticide Evaluation Scheme (WHOPES). 99.1.

Zerba,E. N. 1999. Past and present of Chagas vector control and future needs. World Health Organization, Geneva, Switzerland. (WHO/CDS/WHOPES/GDPP/99.1).

Zerba, E. N., G. Wallace, M. I. Picollo, N. Casabe, S. Licastro, and E. Wood. 1997. Evaluation of $\beta$-cypermethrin for the control of Triatoma infestans. Rev. Panam. Salud Públ. 1: 133-137.

Received 11 May 2012; accepted 15 November 2012. 